\title{
A Hybrid Simulation Model to Predict the Cooling Energy Consumption for Residential Housing in Hong Kong
}

\author{
Kwok Wai Mui, Ling Tim Wong*(D, Manoj Kumar Satheesan and Anjana Balachandran
}

Department of Building Services Engineering, The Hong Kong Polytechnic University, Hong Kong, China; behorace@polyu.edu.hk (K.W.M.); manoj.satheesan@connect.polyu.hk (M.K.S.); anjanajayabala@gmail.com (A.B.)

* Correspondence: beltw@polyu.edu.hk

Citation: Mui, K.W.; Wong, L.T.;

Satheesan, M.K.; Balachandran, A. A Hybrid Simulation Model to Predict the Cooling Energy Consumption for Residential Housing in Hong Kong. Energies 2021, 14, 4850. https:// doi.org/10.3390/en14164850

Academic Editor:

Giovanni Pernigotto

Received: 17 June 2021

Accepted: 4 August 2021

Published: 9 August 2021

Publisher's Note: MDPI stays neutral with regard to jurisdictional claims in published maps and institutional affiliations.

Copyright: (C) 2021 by the authors. Licensee MDPI, Basel, Switzerland. This article is an open access article distributed under the terms and conditions of the Creative Commons Attribution (CC BY) license (https:// creativecommons.org/licenses/by/ $4.0 /)$.

\begin{abstract}
In Hong Kong, buildings consume $90 \%$ of the electricity generated and over $60 \%$ of the city's carbon emissions are attributable to generating power for buildings. In 2018, Hong Kong residential sector consumed $41,965 \mathrm{TJ}(26 \%)$ of total electricity generated, with private housing accounting for $52 \%$ and public housing taking in $26 \%$, making them the two major contributors of greenhouse gas emissions. Furthermore, air conditioning was the major source consuming $38 \%$ of the electricity generated for the residential building segment. Strategizing building energy efficiency measures to reduce the cooling energy consumption of the residential building sector can thus have far-reaching benefits. This study proposes a hybrid simulation strategy that integrates artificial intelligence techniques with a building energy simulation tool (EnergyPlus ${ }^{\mathrm{TM}}$ ) to predict the annual cooling energy consumption of residential buildings in Hong Kong. The proposed method predicts long-term thermal energy demand (annual cooling energy consumption) based on shortterm (hourly) simulated data. The hybrid simulation model can analyze the impacts of building materials, construction solutions, and indoor-outdoor temperature variations on the cooling energy consumed in apartments. The results indicate that using low thermal conductivity building materials for windows and external walls can reduce the annual cooling energy consumption by $8.19 \%$, and decreasing the window-to-wall ratio from $80 \%$ to $40 \%$ can give annual cooling energy savings of up to $18 \%$. Moreover, significant net annual cooling energy savings of $13.65 \%$ can be achieved by changing the indoor set-point temperature from $24{ }^{\circ} \mathrm{C}$ to $26^{\circ} \mathrm{C}$. The proposed model will serve as a reference for building energy efficiency practitioners to identify key relationships between building physical characteristics and operational strategies to minimize cooling energy demand at a minimal time in comparison to traditional energy estimation methods.
\end{abstract}

Keywords: climate change; hybrid EP-ANN model; residential buildings; annual cooling energy prediction

\section{Introduction}

Climate change is real, and it is happening at a tremendous pace. A substantial increase in greenhouse gas (GHG) emissions across the globe has led to adverse impacts on climate, environment, and human health [1,2]. The construction and building sector is considered to be responsible for $38 \%$ of carbon emissions in the world [3]. The final energy consumption associated with buildings was reported to increase from $118 \mathrm{EJ}$ in 2010 to $128 \mathrm{EJ}$ in 2019, and $\mathrm{CO}_{2}$ emissions related to buildings were $10 \mathrm{Gt}$ in 2019, which were the highest ever recorded. Space cooling was noted to be one of the fastest-growing building energy end uses and its associated energy demand has almost tripled since the 1990's. It was deemed solely responsible for about $1 \mathrm{GtCO}_{2}$ emissions and also accounted for $8.5 \%$ of total final electricity consumption [4]. Carbon emissions are a direct contributor driving climate change and related events such as global warming, rise in sea level and extreme weather conditions across the globe. For instance, in Hong Kong, the number of very hot days (temperature at $33^{\circ} \mathrm{C}$ or above) and hot nights (temperature at $28{ }^{\circ} \mathrm{C}$ and above) were 
found to increase whilst the number of cold days (temperature at $12{ }^{\circ} \mathrm{C}$ or below) decreased over the last hundred years [5]. High temperatures and heatwaves associated with extreme heat conditions drove the air conditioning demand which in turn increased electricity requirement worldwide. It is estimated that the energy demand for the buildings are bound to grow by $34 \%$ in the coming two decades at an average rate of $1.5 \%$ [6]. Moreover, the residential sector is likely to contribute about $67 \%$ to energy consumption by 2030 [7]. Residential buildings form a considerable portion of growing energy demand in the world but still, this sector is an undefined energy sink in comparison to other sectors such as industrial, commercial and transport [8]. The energy consumption of other sectors apart from residential has been widely studied and understood due to large economic support and public interest whereas lack of any major incentives was cited for poor initiative towards understanding of energy consumption in residential buildings [9]. These factors emphasize the need to shift focus towards the residential sector for implementing energy saving strategies to have large scale energy conservations and reduce the carbon footprint associated with them.

Hong Kong is one of the most densely populated cities in the world and home to 7.5 million people [10]. While half the world's population is currently residing in cities, another 2.5 billion people are expected to live in cities by 2050 [11]. The population expansion brings along the requirement to provide affordable and sustainable residential buildings to meet the future needs of the population. To meet the housing needs and to make the high-density environment more liveable for the people in the society, Hong Kong has invested much in the development of high-rise residential buildings. Currently, the housing needs of the Hong Kong residents are mainly met by private housing (53\%), public housing (31\%), and housing authority subsidized sale flats (15\%) [12]. According to its housing statistics, residential flats in private housing increased from $1,258,000$ to 1,458,000 whereas flats in public housing grew from 679,000 to 766,000 between 2003 and 2013 [13]. In Hong Kong, buildings consume $90 \%$ of the electricity generated and over $60 \%$ of the city's carbon emissions are attributable to generating power for buildings [14]. As per the 2018 energy end-use data of Hong Kong [15], electricity was the major source of energy consumption amounting to $159,493 \mathrm{TJ}$ (55\%), and the residential sector accounted for $26 \%$ of this total electricity consumption. Moreover, the electricity consumption of the residential sector is more than that of the transport and industrial sector of Hong Kong. The electricity consumption of the residential sector was noted to increase by $13.1 \%$ during the period of 2008 to 2018 as well as an average annual growth rate of $1.2 \%$ during the same period was recorded [15]. Along with the increase in electricity consumption, an increase in population, as well as household size, was also noted and if adequate energy conservation measures are not taken imminently, electricity consumption figures are expected to rise in the future. In 2018, the total energy consumption of residential buildings in Hong Kong was $60,793 \mathrm{TJ}$ and $69 \%$ of this total energy was consumed as electricity, of which $52 \%$ was by private housing and $26 \%$ by public housing [15]. This is indicative that the private and public housings are the two major constituents of GHG emissions from residential segments of Hong Kong. Additionally, it is also essential to note that Hong Kong being a cooling dominant region, $38 \%$ of the electricity consumption was used up for air conditioning of the buildings. The electricity consumption for air-conditioning in the residential sector was also noted to increase by 34\% during the period of 2008 to 2018 [15]. Hence, both decarbonizing of the building sector and enhancing cooling energy efficiency of existing buildings as well as new constructions are prime strategies for meeting Hong Kong's sustainable development goals.

Buildings are one of the major contributors to carbon emissions in the world and switching to a sustainable world requires implementing energy efficiency measures in existing buildings as well as new constructions. As we go through the conception to completion of new buildings and as we perform retrofits to existing buildings to make them more energy-efficient, it is always important to identify key relationships between buildings physical configuration, material properties and operational conditions at a minimal time 
to provide efficient solutions to reduce the overall cost at a later stage. Cooling energy prediction in residential buildings is often complex and influenced by factors such as construction and building materials, climatic conditions, and occupant behaviors [16] Three widely used approaches to predict energy consumption within a building are namely, physical models, data-driven approaches, and hybrid methods $[17,18]$. A physical model utilizes whole building simulation software such as EnergyPlus ${ }^{\mathrm{TM}}$ (EP), TRNSYS, etc. to solve numerical equations to predict energy consumption while considering a building's physical property as well as its associated characteristics. It is also known as the "white box" method as the inner aspects of building physics it works on are quite clear and evident [17]. Moreover, physical simulations through EP do not require historical data of building-related parameters to perform detailed energy analysis. This method, however, is computationally time-consuming and requires expertise to achieve high prediction performance [19]. Additionally, the intricacies associated with the physical method make it infeasible for city-scale energy predictions [20].

With regards to the research and design of residential building energy consumption, there are numerous variables that can influence the overall energy consumption of a building and it is often difficult to handle when these variables are having a non-linear multivariate inter-relationship. To overcome this challenge, it is necessary to have approaches that can efficiently deal with such complex relationships and provide predictions without any significant time lag. To this extent, a data-driven approach, which is an artificial intelligence-based tool can be effectively used to predict the energy consumption associated with buildings. This approach can predict energy consumption without any knowledge of the building physics involved or the building systems associated, and thus is also known as the "black box" method [19]. Some of the well-known data-driven approaches such as support vector machines (SVM), and artificial neural networks (ANN) are capable of providing highly accurate predictions based on input parameters at a reduced computational time [21]. ANN is the most used approach for building energy prediction as shown through previous studies $[9,16,17,22-26]$. Specifically, ANN is capable to process highly non-linear multivariate inter relationships that exist in building energy analysis and it depends solely on the historical data to provide a prediction of building energy performance $[9,25]$. Over the last two decades, ANN has found application in building conception, control optimization, energy consumption prediction, retrofit measures and performance evaluations [27]. Kalogirou et al. [28] used back propagation neural networks to predict the heating load of buildings by developing a model using the consumption data of 255 buildings. Aydinalp et al. [29] utilized a neural network to predict the energy consumption associated with equipment, lighting and space cooling for a residential sector. In this work, the superiority of neural networks over physical methods was illustrated. Yezioro et al. [30] compared the performance of the neural network model for the prediction of energy consumption with four simulation tools and found that accurate results can be found through physical modeling but at the expense of very high computational time. The feasibility of conducting of optimisation procedure was also difficult while adopting physical methods for energy estimation. Another study reported similar conclusions stating that the data driven approaches can provide superior simulation speed when compared with its physical method counterparts [31]. The neural network also finds application in indoor temperature control whereby improvement in thermal comfort can be achieved by the prediction of optimal starting time for heating or cooling systems [32]. Accurate prediction of energy consumption is necessary to efficiently manage a building energy network. Mihalakakou et al. [33] developed a neural network methodology based on atmospheric conditions to predict the energy consumption of a dwelling in Greece. The neural network was trained with five years of hourly energy consumption data. The results of the energy consumption of the house on an hourly basis were deemed highly accurate and reliable. However, as dates were not indicated as an input in this study, it was not possible to account for annual changes. Chou and Bui [34] conducted a study using a building's physical characteristics to predict the heating and cooling load using data-driven 
approaches. They concluded that ANN and support vector regression (SVR) provided better prediction capabilities compared to other techniques such as classification and regression trees or general linear regression. Ahmad et al. [22] predicted the hourly electricity consumption of an HVAC system using ANN and random forest (RF) and found that the ANN is superior compared to RF. Although, prediction performance of the neural network models relies heavily on the database of input-output relationships, where inadequate data can readily degrade its performance [26].

As discussed earlier, two methods namely, physical and data-driven approaches have their own inherent advantages and disadvantages. Although, the coupling of these two methods presents the possibilities to overcome individual shortcomings. The hybrid approach also known as the grey box model couples the physics in the physical method with statistics of the data-driven approach and thereby eliminates the barriers posed by them when performed individually [35]. It not only possesses a shorter simulation time compared to the physical method but also provides physical interpretation between the input-output database that lacks pure statistical approaches. The creation of hybrid models is a critical and time-consuming process particularly when the input-output dataset is created through several building energy simulations. It may be practical to use physical methods for energy estimation for a single building, although hybrid models provide substantial benefits when it is required to thoroughly exploit the influence of several parameter variations on energy consumption for a broad range of buildings at a minimal time [24]. Once the hybrid model for building energy prediction is developed, the energy prediction can be achieved at a negligible time compared to traditional building performance simulation tools. Moreover, the hybrid tool developed through the coupling of building performance simulation tools and data-driven approaches can work well with non-linear data relationships and also make energy consumption predictions for newer configurations, material specifications and operational conditions without going through the rigorous procedure needed in traditional building performance simulation software. Furthermore, the hybrid model has proved to be more time-efficient and predicts accurately by reducing the computational complexities of traditional physical models [36]. This study proposes a hybrid modeling approach to predict the annual cooling energy consumption for residential buildings in Hong Kong. The proposed model, which can help curb carbon emissions, will be used to lay down desirable building physical characteristics and operational strategies for reducing the cooling energy demand in local apartments.

This paper presents the subject in six sections, including the introduction. Section 2 provides a brief overview of the housing stock in Hong Kong, workflow of the modeling and energy simulation process, integration of the neural network with building performance energy simulation tool and explains the overall methodology adopted to estimate the annual cooling energy consumption of residential buildings. The validity and reliability of the hybrid simulation strategy are shown in Section 3. The application of the proposed model to predict the cooling energy consumption for variation in physical configurations, material properties and operational conditions is discussed in Sections 4 and 5. Finally, the conclusion, limitations and future direction of the study are summarized in Section 6.

\section{Methodology}

\subsection{Cooling Energy Consumption}

Hong Kong is in a subtropical region that necessitates space conditioning. Envelope heat gain, ventilation heat gain and internal heat gain (lighting, occupants and electric equipment) contribute to the amount of heat gained in an indoor environment. The annual cooling energy consumption in an apartment is estimated by,

$$
E_{c}=\sum_{\mathrm{k}} \frac{\varnothing_{A C, k}\left(H_{\text {en }}+H_{\text {in }}+H_{\text {vent }}\right)_{k}}{C O P_{k}}
$$


where $\varnothing_{A C, k}$ is the hourly air conditioner operation schedule in a year for $k=1,2, \ldots$, $8760 \mathrm{~h}, H_{e n}$ is the hourly envelope heat gain, $H_{\text {in }}$ is the internal heat gain and $H_{\text {vent }}$ is the ventilation heat gain [37].

$H_{\text {in }}$ is the internal heat gained from lighting and electric equipment, it can be expressed by Equation (2) in terms of floor area $A_{f l}$ and the sum of equipment power density $E_{p d}$ and lighting power density $L_{p d}[38]$.

$$
H_{\text {in }}=\left(E_{p d}+L_{p d}\right) \times A_{f l}
$$

The ventilation heat gain $H_{\text {vent }}$ can be expressed as the sum of sensible load $L_{s e n}$ and latent load $L_{\text {lat }}$,

$$
H_{\text {vent }}=L_{\text {sen }}+L_{\text {lat }} ;\left\{\begin{array}{l}
L_{\text {sen }}=N_{k} \rho V_{\text {vent }} C_{p a}\left(T_{a}-T_{o}\right) \\
L_{\text {lat }}=N_{k} \rho V_{\text {vent }} h_{f g}\left(w_{a}-w_{o}\right)
\end{array}\right.
$$

where $N_{k}$ is the number of occupants at hour $k$, air density $\rho=1.2 \mathrm{~kg} \mathrm{~m}^{-3}$, latent heat of evaporation $h_{f g}=2436 \mathrm{~kJ} \mathrm{~kg}^{-1}$, heat capacity of air $C_{p a}=1.01 \mathrm{~kJ} \mathrm{~kg}^{-1}{ }^{\circ} \mathrm{C}^{-1}, T_{a}\left({ }^{\circ} \mathrm{C}\right)$ is indoor temperature, and $T_{o}\left({ }^{\circ} \mathrm{C}\right)$ is the outdoor temperature. The average ventilation rate $V_{\text {vent }}=3 \mathrm{Ls}^{-1} \mathrm{ps}^{-1}$ between the window and split type room air conditioner is used [39]. The indoor moisture content $w_{a}\left(\mathrm{~kg} \mathrm{~kg}^{-1}\right.$, dry air) can be estimated based on the psychrometric chart while the outdoor moisture content $w_{0}\left(\mathrm{~kg} \mathrm{~kg}^{-1}\right.$, dry air) can be estimated using Equation (4), where $p_{w}$ is the vapor pressure $(\mathrm{kPa}), p_{w s}$ is the saturated vapor pressure $(\mathrm{kPa})$ and $R_{h, o}$ is the outdoor relative humidity (\%),

$$
w_{o}=\frac{p_{w}}{101.325-p_{w}} \times 0.622 ; p_{w}=\frac{R_{h, o}}{100} \times p_{w s}
$$

Air conditioners used in residential buildings are reported to have a maximum coefficient of performance (COP) of 2.9 [40]; their cooling efficiency, which will drop with hourly sensible heat ratio $S H R_{k}$, can be calculated by Equation (5) [41].

$$
C O P_{k}=\frac{\left(S H R_{k}+0.45\right)^{4.9}}{1.1}+0.75
$$

In order to achieve a realistic prediction of cooling energy consumption, occupant behavior should be taken as an essential factor. An occupant load survey of 720 households of government and non-government funded residential buildings in Hong Kong was conducted by Wong and Mui (2006) and using their data, the hourly occupant load $N_{k}$ can be estimated by Equation (6), where $\psi_{k}$ is the hourly occupant load variation, $N_{\max }$ is the maximum number of occupants in an apartment, $O_{a}\left(\mathrm{ps} \mathrm{m}^{-2}\right)$ is the occupant area ratio and $A_{f l}\left(\mathrm{~m}^{2}\right)$ is the apartment floor area [42].

$$
N_{k}=N_{\max } \psi_{k} ; N_{\max }=O_{a} A_{f l}
$$

\subsection{Prediction of Envelope Heat Gain through a White Box Model}

Hong Kong has a high-density living environment with a land population density of about 6700 people $/ \mathrm{km}^{2}$ [43]. High-rise residential buildings cater to meet the chronic shortage of housing in Hong Kong and also make the highly-dense environment more livable. The private housing sector meets the housing needs of $53 \%$ of the households in the city whereas public housing provides shelter to $31 \%$ and about $15 \%$ of the general public utilize subsidized sale flats under the home ownership scheme [12]. As discussed earlier, the private and public housings sectors are also the two major constituents of GHG emission under the residential building segment. Hence, we considered the public and private housing stock of Hong Kong to analyze different configurations of building physical characteristics and operational strategies that could reduce the carbon emission associated with these buildings in this study. The public housing sector in Hong Kong 
follows five standard block layouts namely, Concord, Harmony, New cruciform, Slab, and Trident as shown in Figure 1 [44]. The housing layouts in the private sector also closely follow designs adopted by the public housing but more randomness to building design layout is observed. Additionally, while comparing with public housing, provision for having higher apartment floor area, window to wall ratio are often attributed with the design of buildings in the private housing sector of Hong Kong.

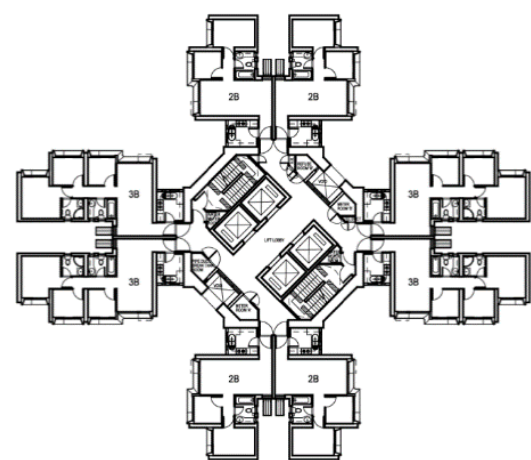

(a)

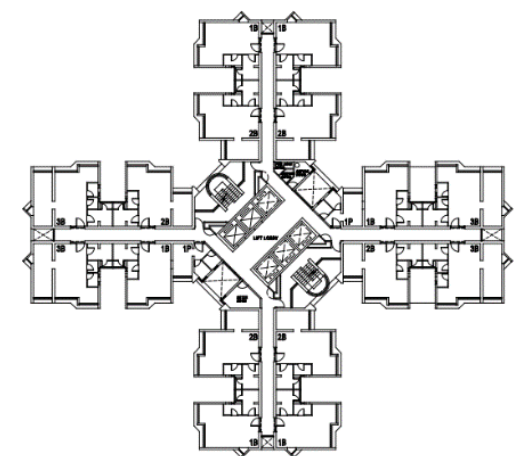

(b)

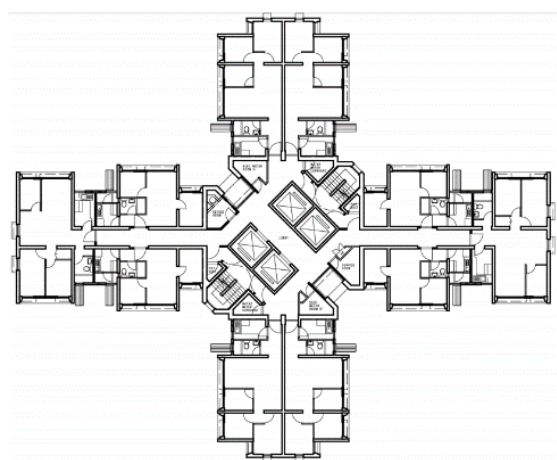

(c)

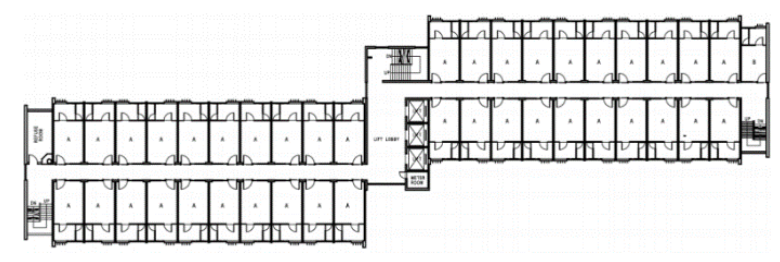

(d)

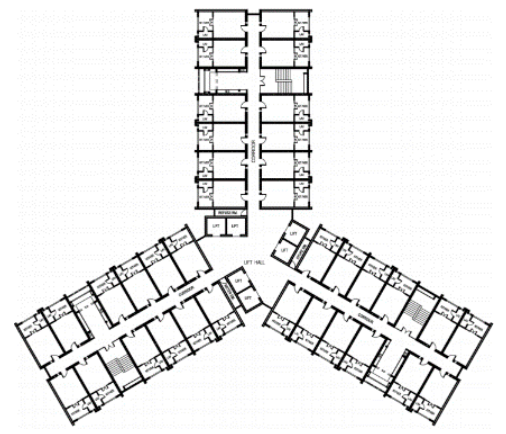

(e)

Figure 1. Standard public housing block layouts in Hong Kong: (a) Concord; (b) Harmony; (c) New Cruciform; (d) Slab; (e) Trident.

To minimize the heat gain from the outdoor environment, an effective envelope design is necessary for residential buildings. Envelope heat gain and fenestration are the two main contributors to the cooling energy demand in buildings [45]. In this study, the range of input parameters listed in Table 1 was extracted from design standards, Hong Kong residential property websites, and open literature data [46-50]; the apartment models were created in SketchUp 2019; and the building energy simulation was performed through the OpenStudio $^{\circledR}(\mathrm{OS})$ cross-platform tool that supports EnergyPlus ${ }^{\mathrm{TM}}(\mathrm{EP})$, a superior whole building energy simulation program in terms of user-configurable modular system and variable time step simulation in comparison to its predecessor programs-BLAST and DOE(2) [51]. OpenStudio ${ }^{\circledR}$ is an EnergyPlus/Radiance framework to easily extend the base capability of EnergyPlus ${ }^{\mathrm{TM}}$ for diverse purposes and its abstractions of EP make it more convenient to comprehend new energy models as well as automate a wide array of energy analyses' [52,53]. It is a strategic component of the United States Department of Energy to leverage the use of advanced building energy modeling specifically EnergyPlus ${ }^{\mathrm{TM}}$ for the design and operation of buildings. The base energy model created in OpenStudio ${ }^{\circledR}$ can be then used for creating design alternatives in the parametric analysis tool (PAT) available within the OpenStudio ${ }^{\circledR}$ software package. The workflow of the modeling and energy simulation process adopted in this study is illustrated in Figure 2. 
Table 1. Input parameters for envelope heat gain prediction.

\begin{tabular}{cc}
\hline Input Parameters & Ranges \\
\hline Outdoor temperature, $T_{o}\left({ }^{\circ} \mathrm{C}\right)$ & Weather data of Hong Kong 1989 \\
Day of a year & $1-365$ \\
Hour of a day & $1-2$ \\
Air temperature, $T_{\mathrm{a}}\left({ }^{\circ} \mathrm{C}\right)$ & $20-30$ \\
Window area, $A_{w d}\left(\mathrm{~m}^{2}\right)$ & $2.32-58.179$ \\
External wall area, $A_{e n}\left(\mathrm{~m}^{2}\right)$ & $5.659-133.63$ \\
Apartment floor area, $A_{f l}\left(\mathrm{~m}^{2}\right)$ & $12.624-150.04$ \\
Orientation $\left({ }^{\circ}\right)$ & $0-360$ \\
Window $U$-value, $U_{w d}\left(\mathrm{~W} /\left(\mathrm{K}^{2} \cdot \mathrm{m}^{2}\right)\right)$ & $4.2-6.9$ \\
Wall $U$-value, $U_{w l}\left(\mathrm{~W} /\left(\mathrm{K} \cdot \mathrm{m}^{2}\right)\right)$ & $0.4-2.9$ \\
Shading coefficient, $S_{c}$ & $0.4-0.97$ \\
Vertical shadow angle, $\sigma_{v}\left({ }^{\circ}\right)$ & $0.0-89.9$ \\
\hline
\end{tabular}

SketchUp

- Creation of OpenStudio 3D model with SketchUp plugin.

- Assign space type and its attributes.

- Assign thermal zone and thermostat.

- Save and load the model into OpenStudio.
OpenStudio - EnergyPlus

- Set weather file and design days

- Set the schedules.

- Create materials and assign materials to construction set.

- Assign construction set, loads, and surface attributes such as outside boundary condition.

- Assign temperature set-point and humidity control for indoor space.

- Run the EnergyPlus simulation.

- Save the OpenStudio base model.

Parametric Analysis Tool

- Open the OpenStudio base model and associated files.

- Create OpenStudio, EnergyPlus and reporting measures.

- Create design alternatives from measures to the base model.

- Run the EP simulation for the design alternatives.

Figure 2. Workflow of the modeling and energy simulation process.

The parametric analysis tool provides the capability and flexibility to manually compare numerous design alternatives stemming from various measures/scripts generated within the tool [53]. The measure is a script program written in ruby that provides the functionality to change the insulation properties of walls, modify window to wall ratios, operational settings, occupancy schedules, generate detailed reports of input-output of energy models and so on [54,55]. For instance, by using a measure named Add Remove Or Replace Window Overhangs, a window overhang can easily be generated on a prototype room model as shown in Figure 3. The script file is too long to be listed here but it is easily available from the building component library (BCL) for users, which is an online repository that contains building components and measures [56]. Hence, PAT tool with its diverse functionality was utilized to run EP simulations for different combinations of apartment layouts, operational conditions and material properties. 


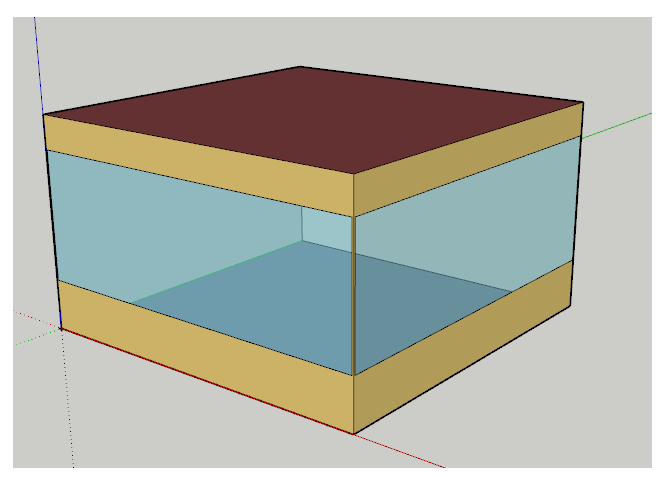

(a)

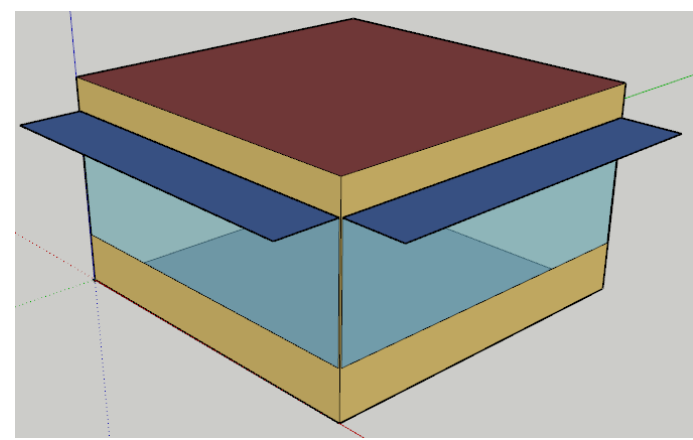

(b)

Figure 3. Illustration of a simple room model: (a) Before application of overhang measure; (b) After application of overhang measure.

A total of 620,000 random configurations of physical and operational parameters (i.e., the input parameters in Table 1) were employed. The weather data of Hong Kong in 1989 was obtained from the Hong Kong Observatory for the EP simulations [57]. A database containing the input parameter ranges and their corresponding hourly envelope heat gains generated by the simulations was used to train the ANN model as illustrated in Figure 4.

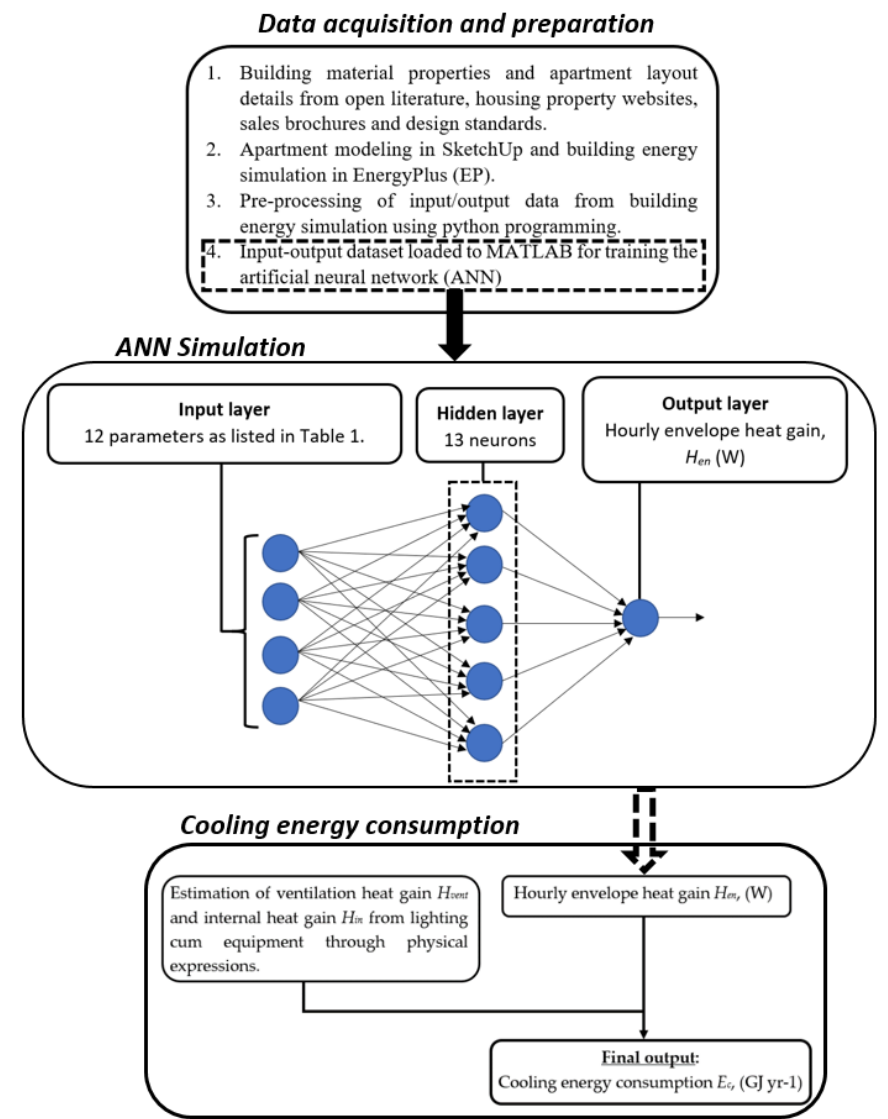

Figure 4. Schematic of the proposed cooling energy consumption estimation model.

\subsection{Neural Network}

The generalization of the neural connection of the human brain into a mathematical model leads to the development of an artificial neural network. The emergence of technological advancements in the last 20 years has paved the way for ANN to find applications in innumerable fields such as aerospace, energy, medical science, etc. [58,59]. The building 
sector is also not immune to the adoption of artificial neural networks and it is applied to different stages of a building project, including conception, control optimization, energy consumption prediction, retrofitting and performance evaluation $[17,27]$. While dealing with the energy associated with buildings, it is essential to employ a model that can consider non-linear multivariate interrelationships of parameters in a "noisy environment". The exponential growth of computing capacity and processing speeds have increased the applicability and reliability of ANN to predict building-related energy performance many folds [58]. Additionally, the capability of ANN to process non-linear input-output relationships with high precision had made it a popular choice over conventional theoretical and empirical methods for building energy efficiency practitioners [16,25]. It is also a very robust system that is noise-immune in nature [36,60]. When building an ANN model for accurate predictions, the choice of neural network architecture and its intrinsic hierarchical characteristics is important. This study proposes a hybrid EP-ANN model to predict the hourly envelope heat gains for private and public residential buildings in Hong Kong. The model uses the backpropagation algorithm (BPA) as a basis. The dataset for training this BPA-based neural network contains abstractions obtained through input-output data from the EP simulations. A conventional three-layer feedforward network which comprises the input layer (12 neurons), the hidden layer (13 neurons) and the output layer (1 neuron) is employed. In addition, the number of neurons in the hidden layer is varied from 12 to 14 with a step increment of one. The Levenberg-Marquardt algorithm (LMA) is used to train the input vectors and their corresponding target vectors. LMA, designed to approach second-order training speed without directly computing the Hessian matrix, outperforms other models such as gradient descent and conjugate gradient methods as shown in previous research studies $[61,62]$. The Hessian matrix $\left(H_{m}\right)$ is approximated by,

$$
\begin{gathered}
H m=J^{T} J \\
\beta=J^{T} e
\end{gathered}
$$

where $J$ is the Jacobian matrix, $\beta$ is the gradient and $e$ is the vector of network errors. The approximation of the Hessian matrix can be obtained by a Newton-like update method,

$$
x_{n+1}=x_{n}-\left[J^{T} J+\mu I\right]^{-1} J^{T} e
$$

where $\mu$ is a scalar known as the Marquardt adjustment parameter. When $\mu=0$, Equation (9) behaves like Newton's method using the approximate Hessian matrix; when $\mu$ is large, it becomes gradient descent with a small step size.

The trained network can be tested with a set of test data to check the generalized predictability of the neural network. To enhance the generalization ability of the trained neural network, the trainbr function (LMA based Bayesian regularization technique in MATLAB R2020b, MathWorks, Natick, MA, USA) is applied [63,64]. The conventional error function and weight decay components are included in the objective function and Bayes' rule is used to optimize the regularization parameters in the function. The weights and biases are a Gaussian distribution with random variables. The tan-sigmoid activation function as expressed in Equation (10) is used in the hidden layer and a linear transfer function $f_{\text {pureline }}$ as shown in Equation (12) is applied to the output layer.

$$
\begin{gathered}
a_{j}=f_{\text {tansig }}\left(n_{j}\right)=\frac{2}{1+\exp \left(-2 n_{j}\right)}-1 ; \\
n_{j}=\sum_{j=1}^{10} \sum_{i=1}^{12} P_{i} I W_{j, i}+b_{j}
\end{gathered}
$$

where $i, j$ are the numbers of elements in the input vector and hidden layer respectively, $a_{j}$ is the output from each neuron of the hidden layer, $n_{j}$ is the net input vector, $P_{i}$ is the 
input element of the input layer where $i$ varies from 1 to $12, I W$ is the input weight matrix where each $P_{i}$ in the hidden layer is connected to its corresponding neuron, $P_{i} I W_{j, i}$ is the weighted input value and $b_{j}$ is the bias.

$$
H_{\text {en }}=f_{\text {pureline }}\left(n_{\text {out }}\right)=n_{\text {out }} ; n_{\text {out }}=\sum_{j=1}^{10} a_{j} L W_{j}+b_{\text {out }}
$$

where $H_{e n}$ is the hourly envelope heat gain $(\mathrm{W}), f_{\text {pureline }}$ is the linear transfer function, $n_{\text {out }}$ is the net output value, $L W_{j}$ is the layer weight index and $a_{j} L W_{j}$ is the output layer weighted value.

\section{Model Validation}

The proposed hybrid model was tested with different design and operational configurations for validation. The ANN was trained with one hidden layer and the number of neurons in the hidden layer was varied from 12 to 14 . The dataset was split into 70:30 ratios for training and testing the neural network. A big advantage of the LMA based Bayesian regularization technique is that it does not essentially require a validation set, hence more data could be used for training the network [65-67]. Figure 5 exhibits the goodness of fit between EP and ANN results for various configurations as listed in Table 2. The selection of a number of hidden neurons was performed through a trial-and-error basis $[23,24,58]$ and it was found that with 13 hidden neurons, the ANN gave a better correlation $\left(R^{2}=0.947\right)$ and a Root Mean Squared Error (RMSE) of 0.0389, indicating a well-trained and well-equipped neural network for predicting envelope heat gains.

The validity of the hybrid simulation strategy used in this study was also tested using the open literature data given by a study performed by Cheung et al. [38] a lighting power density $\left(L_{p d}\right)$ of $18 \mathrm{~W} / \mathrm{m}^{2}$, an equipment power density $\left(E_{p d}\right)$ of $24 \mathrm{~W} / \mathrm{m}^{2}$, and an air conditioner operation schedule $\phi_{k}$ during the time period from 19:00 to 07:00 on the next day. Figure 6 shows that the prediction results of annual cooling energy consumption produced by the hybrid simulation approach and by Cheung et al.'s [38] study have similar trends. The reason why the former results were higher (approximately $8.5 \%$ ) may be due to the COP difference. A constant COP of 2.5 was used in Cheung et al.'s [38] study whereas a constant and lower hourly $\mathrm{COP}_{k}$ (as low as 1.5; especially during humid summer nights with a low sensible heat ratio $\left.\left(S H R_{k}\right)\right)$ was recorded in this study.

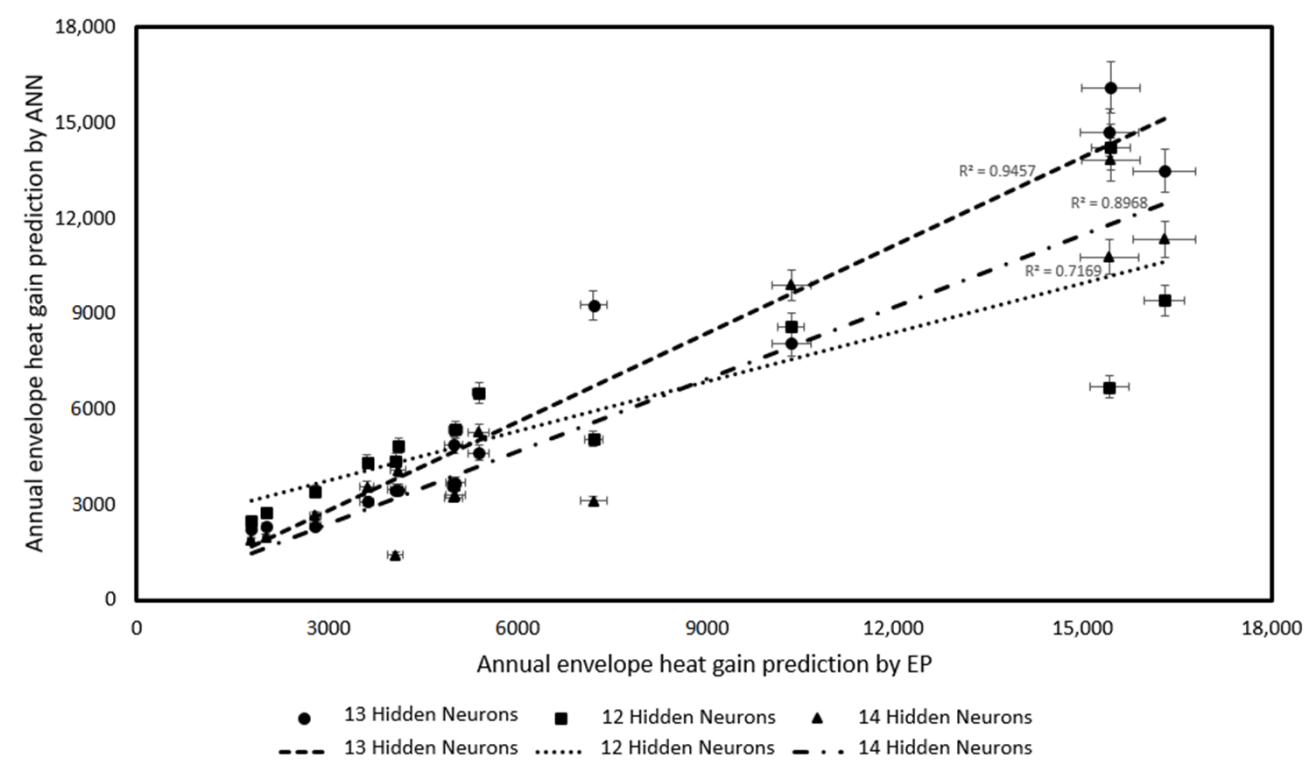

Figure 5. Comparison between artificial neural network (ANN) and EnergyPlus (EP) predictions of the annual envelope heat gain $\left(\mathrm{kW} \mathrm{yr}^{-1}\right)$. 
Table 2. Apartment details and other parameters for model validation.

\begin{tabular}{|c|c|c|c|c|c|c|c|c|c|}
\hline Case & $\begin{array}{l}\text { Floor Area } \\
\left(\mathrm{m}^{2}\right)\end{array}$ & $\begin{array}{c}\text { External } \\
\text { Wall Area } \\
\left(\mathrm{m}^{2}\right)\end{array}$ & $\begin{array}{l}\text { Window } \\
\text { Area }\left(\mathrm{m}^{2}\right)\end{array}$ & $\begin{array}{c}\text { Indoor } \\
\text { Set-point } \\
\text { Temperature } \\
\left({ }^{\circ} \mathrm{C}\right)\end{array}$ & $\begin{array}{c}\text { Wall } \\
\text { U-Value } \\
\left(\mathrm{W} /\left(\mathrm{K} \cdot \mathrm{m}^{2}\right)\right)\end{array}$ & $\begin{array}{c}\text { Window } \\
\text { U-Value } \\
\left(\mathrm{W} /\left(\mathrm{K} \cdot \mathrm{m}^{2}\right)\right)\end{array}$ & $\begin{array}{l}\text { Shading } \\
\text { Coefficient }\end{array}$ & $\begin{array}{c}\text { Orientation } \\
\left(\left(^{\circ}\right)\right.\end{array}$ & $\begin{array}{c}\text { Vertical } \\
\text { Shadow } \\
\left.\text { Angle ( }{ }^{\circ}\right)\end{array}$ \\
\hline 1 & 30 & 22.8 & 12.3 & 22 & 0.5 & 5 & 0.9 & 180 & 0 \\
\hline 2 & 35.8 & 31.9 & 7.6 & 24 & 2.9 & 6.9 & 0.97 & 45 & 75.3 \\
\hline 3 & 65 & 36.1 & 15.5 & 26 & 1.5 & 5 & 0.9 & -90 & 40 \\
\hline 4 & 30 & 22.8 & 12.3 & 24 & 1.5 & 5.8 & 0.7 & 90 & 70 \\
\hline 5 & 110 & 63.8 & 36.9 & 22 & 1.5 & 4.2 & 0.9 & 0 & 70 \\
\hline 6 & 30.4 & 30.4 & 4.2 & 24 & 2.9 & 6.9 & 0.97 & 45 & 75.3 \\
\hline 7 & 145 & 75.2 & 40.5 & 24 & 1.5 & 5 & 0.7 & 0 & 70 \\
\hline 8 & 23.9 & 32.8 & 5.1 & 27 & 2 & 4.2 & 0.7 & -45 & 40 \\
\hline 9 & 35.9 & 40 & 9.2 & 24 & 2.9 & 6.9 & 0.97 & 45 & 75.3 \\
\hline 10 & 15.1 & 21.1 & 4.6 & 24 & 2.9 & 6.9 & 0.97 & 45 & 75.3 \\
\hline 11 & 120 & 70 & 35.1 & 28 & 0.5 & 4.2 & 0.5 & 180 & 0 \\
\hline 12 & 135 & 48.3 & 63.2 & 26 & 0.5 & 5.8 & 0.7 & 0 & 70 \\
\hline 13 & 52.1 & 46.4 & 11.5 & 26 & 0.5 & 5.8 & 0.5 & -90 & 75.3 \\
\hline 14 & 19.7 & 17.6 & 3.7 & 24 & 2.9 & 6.9 & 0.97 & 45 & 75.3 \\
\hline
\end{tabular}

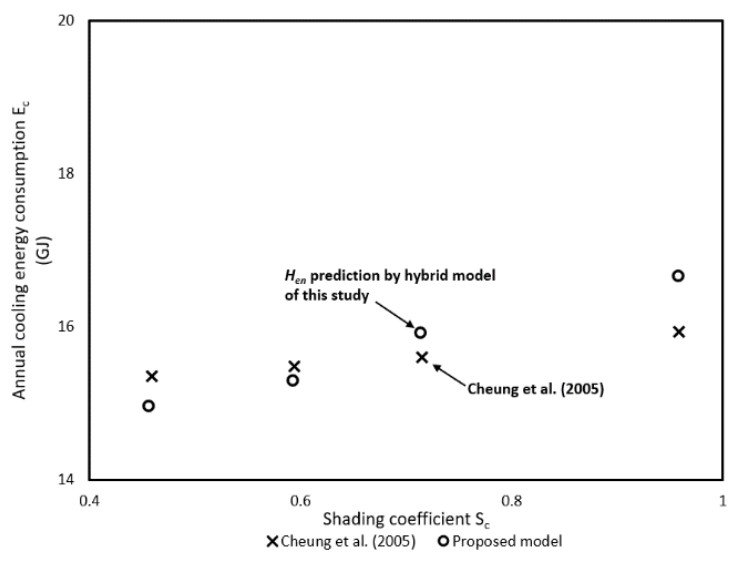

(a)

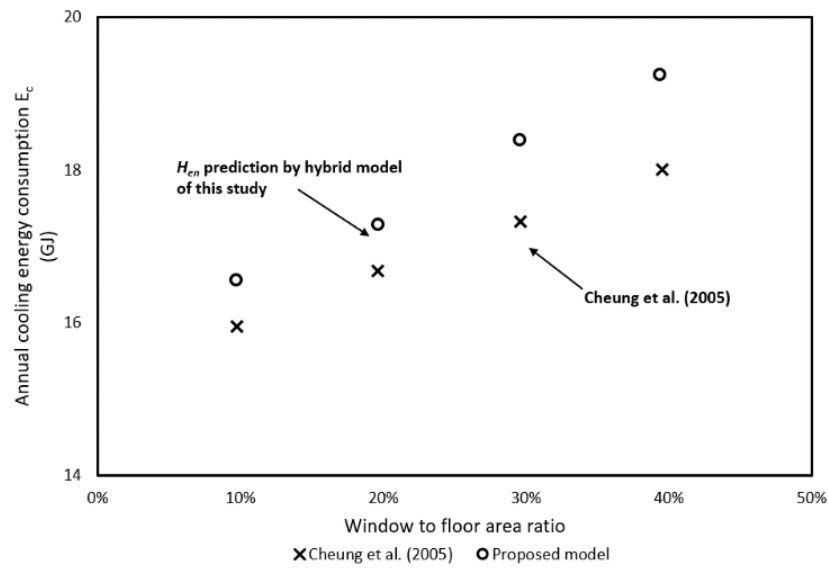

(b)

Figure 6. Comparison of results by the proposed model and Cheung et al.'s study [38]: (a) Annual cooling energy consumption $\left(E_{c}\right) \mathrm{v} / \mathrm{s}$ Shading coefficient $\left(S_{c}\right)$; (b) Annual cooling energy consumption $\left(E_{c}\right)$ vs. window-to-floor area ratio.

\section{Results}

\subsection{Impacts of Building Materials and Construction Solutions on Cooling Energy Consumption}

In this study, the insulating properties of walls and windows were derived from various design standards and open access databases [21,30-34]. Figure 7 illustrates the effect of window insulation on the annual cooling energy consumption in an apartment with a floor area of $60 \mathrm{~m}^{2}$, a range of window U-values varied from 4.2 to $6.5 \mathrm{~W} /\left(\mathrm{K} \cdot \mathrm{m}^{2}\right)$, and a range of shading coefficients varied from 0.4 to 0.8 . It is observed that the apartment cooling energy load increases with the window U-value. For instance, with a shading coefficient of 0.6 , the annual cooling energy consumption values are $8.8 \mathrm{GJ}$ and $9.19 \mathrm{GJ}$ for window $\mathrm{U}$-values of $4.2 \mathrm{~W} /\left(\mathrm{K} \cdot \mathrm{m}^{2}\right)$ and $5.5 \mathrm{~W} /\left(\mathrm{K} \cdot \mathrm{m}^{2}\right)$, respectively, giving an increase of $3.4 \%$ in the annual cooling energy load. Similarly, with the same window U-value, the cooling energy requirement presents an upward trend following the increase in shading coefficient. Moreover, Figure 7 shows that $8.85 \mathrm{GJ}$ is the lowest annual cooling energy consumption estimated for a U-value of $4.2 \mathrm{~W} /\left(\mathrm{K} \cdot \mathrm{m}^{2}\right)$ with a shading coefficient of 0.4 , while $9.58 \mathrm{GJ}$ is the highest cooling energy consumption estimated for a U-value of $6.5 \mathrm{~W} /\left(\mathrm{K} \cdot \mathrm{m}^{2}\right)$ with a shading coefficient of 0.8 . In other words, a reduction of $8.19 \%$ in annual cooling energy usage can be achieved when windows combining both a low U-value (e.g., $\left.4.2 \mathrm{~W} /\left(\mathrm{K} \cdot \mathrm{m}^{2}\right)\right)$ and a low shading coefficient (e.g., 0.4) are installed. 


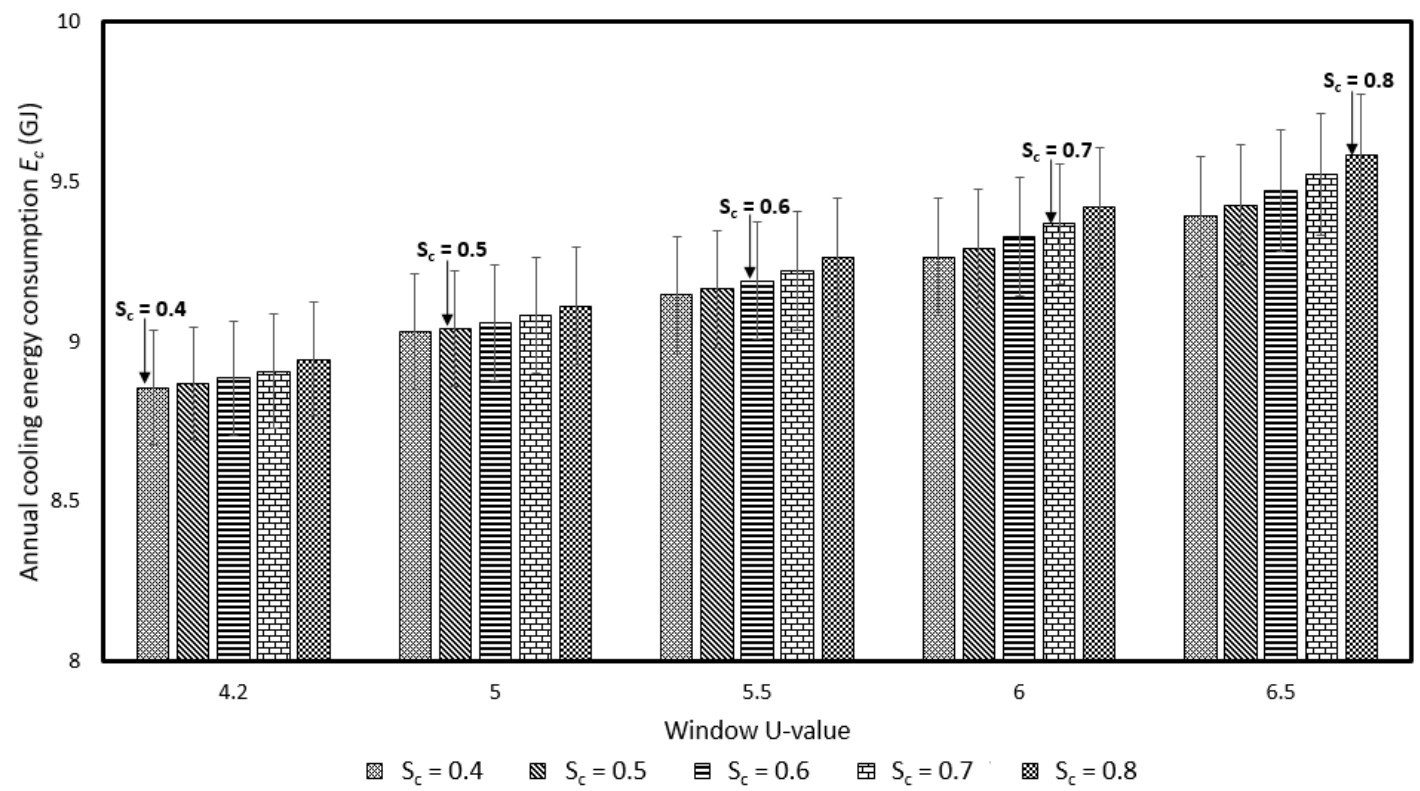

Figure 7. Annual cooling energy consumption with variation in window $\mathrm{U}$-value $\left(\mathrm{W} /\left(\mathrm{K} \cdot \mathrm{m}^{2}\right)\right)$ and shading coefficient $S_{c}$.

The impact of external wall insulation on the annual cooling energy consumed in an apartment was also taken into consideration. Figure 8 exhibits the cooling energy used in apartments when external wall U-values ranged from 0.4 to $2.5 \mathrm{~W} /\left(\mathrm{K} \cdot \mathrm{m}^{2}\right)$ and floor areas of $30 \mathrm{~m}^{2}, 60 \mathrm{~m}^{2}$ and $90 \mathrm{~m}^{2}$. It can be seen in the figure that with a U-value of 2.5 , the annual cooling energy usage in the $30 \mathrm{~m}^{2}$ apartment is $4.28 \mathrm{GJ}$ while the usage in the $90 \mathrm{~m}^{2}$ apartment is 14.42 GJ. According to Figure 8, an average reduction of $7.56 \%$ in the annual cooling energy consumption can be reached in all apartments when the U-value is varied from $2.5 \mathrm{~W} /\left(\mathrm{K} \cdot \mathrm{m}^{2}\right)$ to $0.4 \mathrm{~W} /\left(\mathrm{K} \cdot \mathrm{m}^{2}\right)$.

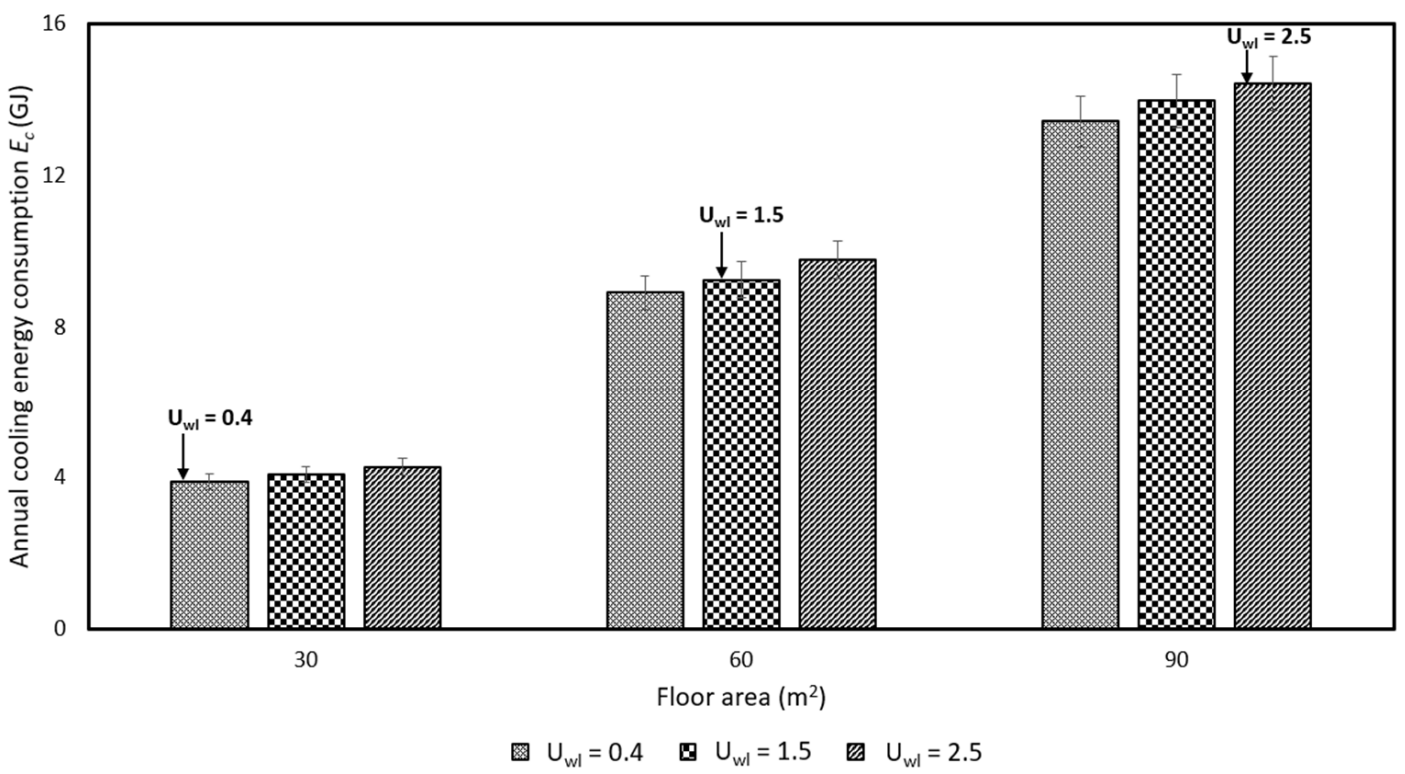

Figure 8. Annual cooling energy consumption with variation in external wall $\mathrm{U}$-value $\left(\left(\mathrm{W} /\left(\mathrm{K} \cdot \mathrm{m}^{2}\right)\right)\right.$.

The window-to-wall ratio (WWR) is an important construction arrangement that creates not only good visual aesthetics but also considerable effects on envelope heat gain in an apartment. Figure 9 depicts the estimation of annual cooling energy consumption for a $60 \mathrm{~m}^{2}$-apartment with WWRs ranging from $20 \%$ to $80 \%$ (with a step of $20 \%$ ). The lowest and highest cooling energy consumption values are 7.85 GJ at WWR $=20 \%$ and 
$9.96 \mathrm{GJ}$ at $\mathrm{WWR}=80 \%$ respectively. The results indicate that increasing the WWR from $20 \%$ to $80 \%$ increases the annual cooling energy consumption. On the other hand, while maintaining adequate ventilation and visual aesthetics requirements, a reduction of $18 \%$ in annual cooling energy consumption can be achieved by decreasing the WWR from $80 \%$ to $40 \%$.

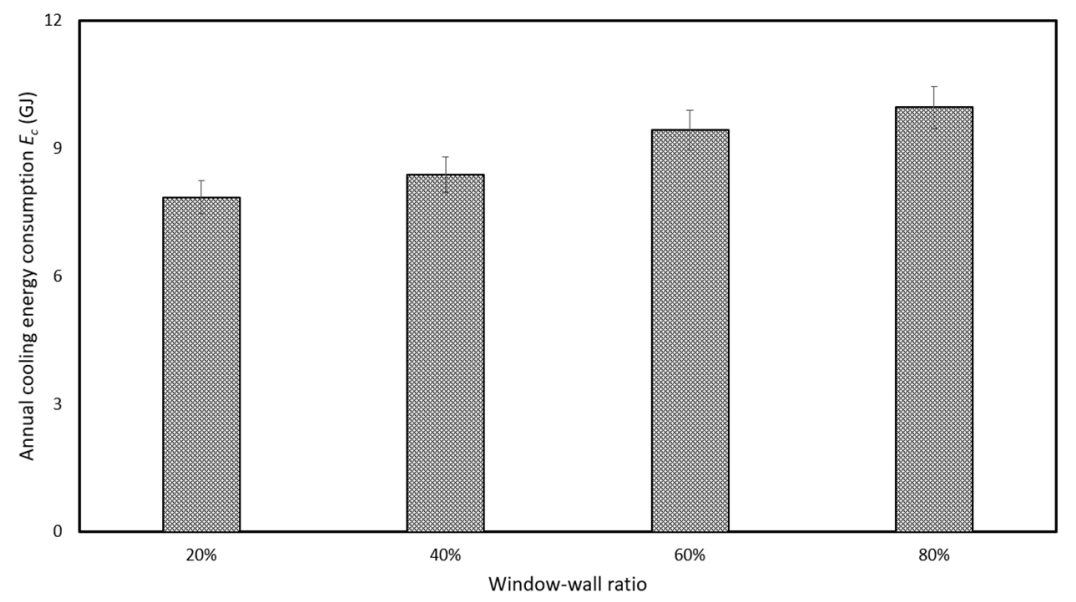

Figure 9. Annual cooling energy consumption with variation in window-wall ratio.

\subsection{Indoor Temperature Set-Point against Global Warming}

Figure 10 illustrates the forecast of annual cooling energy consumption for a $60 \mathrm{~m}^{2}$ apartment using the outdoor temperature $T_{o}$ variation based on the weather data of Hong Kong in 1989 and a range of indoor set-point temperatures $T_{\text {in }}$ from $23{ }^{\circ} \mathrm{C}$ to $26^{\circ} \mathrm{C}$. The variation of outdoor temperature due to global warming was also considered. The highest annual cooling energy consumption (10.35 GJ) and the lowest annual cooling energy consumption $(7.63 \mathrm{GJ})$ can be observed at indoor set-point temperatures of $23{ }^{\circ} \mathrm{C}$ and $26{ }^{\circ} \mathrm{C}$ respectively. While reductions of $26 \%$ and $13.65 \%$ in the annual cooling energy consumption can be achieved by changing the indoor set-point temperatures from $23^{\circ} \mathrm{C}$ to $26^{\circ} \mathrm{C}$ and $24{ }^{\circ} \mathrm{C}$ to $26^{\circ} \mathrm{C}$ respectively, reductions of $21 \%$ and $13.03 \%$ can be attained by increasing the indoor set-point temperatures from $23^{\circ} \mathrm{C}$ to $24.5^{\circ} \mathrm{C}$ and $24{ }^{\circ} \mathrm{C}$ to $25.5^{\circ} \mathrm{C}$ respectively. In the indoor temperature range $23-25^{\circ} \mathrm{C}$, every increment of $T_{\text {in }}$ by $0.5^{\circ} \mathrm{C}$ will give a reduction of $7.66 \%$ in annual cooling energy consumption; if the indoor temperature is above $25^{\circ} \mathrm{C}$, then every increment of $T_{\text {in }}$ by $0.5^{\circ} \mathrm{C}$ will give a reduction of $2.5 \%$ in annual cooling energy consumption. Putting global warming into perspective, when the outdoor temperature increases by $1{ }^{\circ} \mathrm{C}$, an increase of $4 \%$ in annual cooling energy load from the existing level are estimated for maintaining the indoor set-point temperature at $24{ }^{\circ} \mathrm{C}$, whereas an increase of $6 \%$ from the existing level is estimated for maintaining the indoor set-point temperature at $23{ }^{\circ} \mathrm{C}$. 


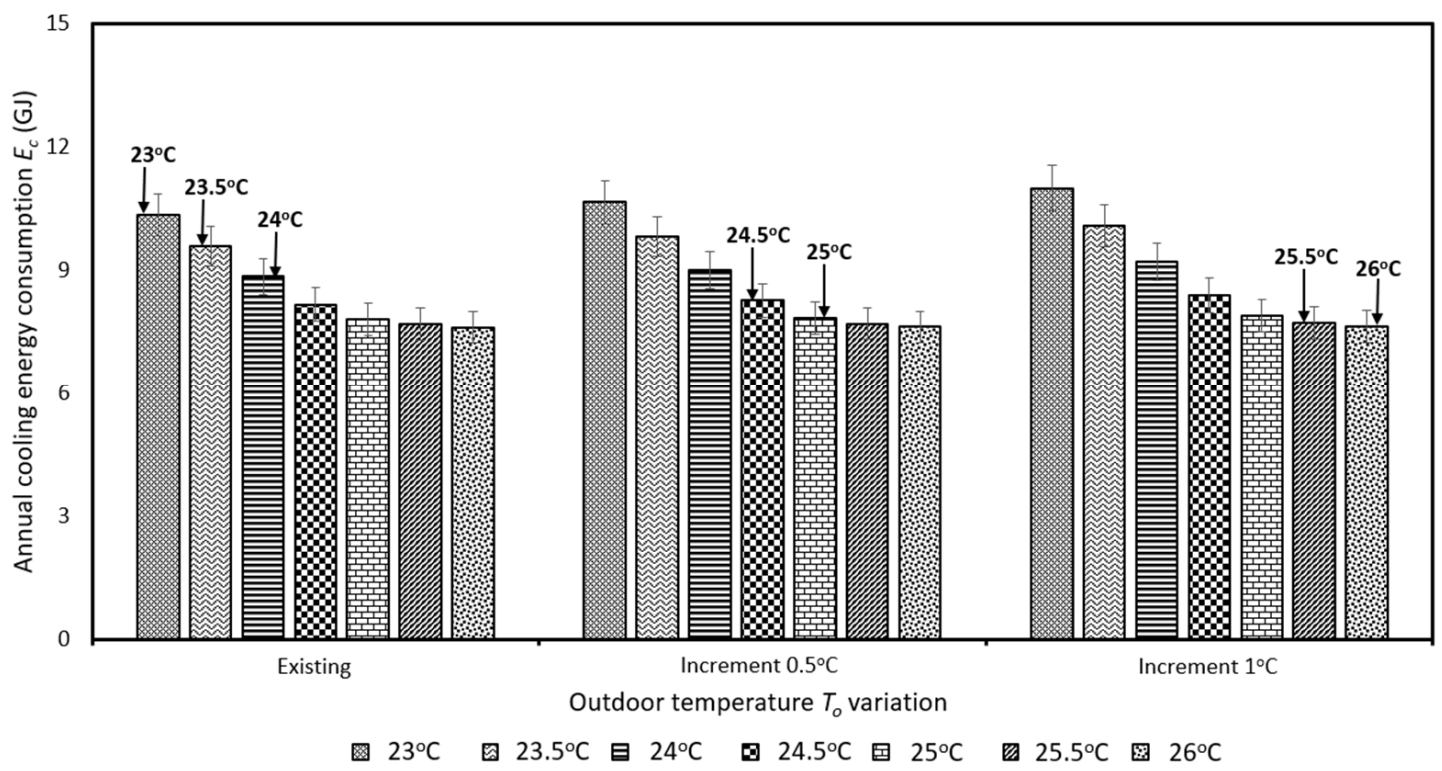

Figure 10. Annual cooling energy consumption forecast based on indoor set-point temperature.

\section{Discussions}

The heat transfer through the building envelope is primarily an important component that can influence the electricity use related to the cooling of an apartment to maintain thermal comfort for its occupants. It is indicative from this study that the selection of Uvalue of building material is critical as it can influence the cooling energy consumption of an apartment. It was noted that as the U-value of the external wall increased, a corresponding increase in cooling energy consumption was noted for the different floor areas considered in this study. Needless to say that there exists a linear relationship between cooling energy consumption and the U-value of building material. The cooling energy consumption of the apartment almost doubled as the floor area doubled for the same U-value of the wall. Taking this scenario into consideration it is imperative that if ideal thermal insulations are not provided on the building envelope, the cooling energy consumption of apartments with large floor areas can be very high. On another note, as U-value can be a decisive factor in restricting the amount of heat transferred to the indoor environment, buildings with natural ventilation can avoid thermal discomfort by upgrading the U-value of the building envelope.

The shading coefficient $S_{c}$ is an index of thermal insulation associated with glazing; the higher the $S_{c}$, the lower will be the resistance to heat transfer through solar radiation. The window $\mathrm{U}$-value and $S_{c}$ play a major role in the increase/decrease in cooling energy consumption as observed in this study. It is to be noted that the choice of tinted or low-emissivity glass with lower $S_{c}$ values compared to standard clear glass is always preferable for buildings located in the sub-tropical climatic region. At the same time, for a window with a fixed U-value altering the shading coefficient can aid in reducing the cooling energy consumption. In essence, it is essential to interpret from this study that mix and match of $U$-value and $S_{c}$ can be achieved based on the need, for instance, if passive solar heating energy is desired, window coupled with high $S_{c}$ and low U-value can be specified. It is recommended that for buildings located in sub-tropical climatic zones, the usage of windows with lower U-value and lower $S_{c}$ values can dramatically cut the cooling energy consumption.

To draw further emphasis on the impact of building envelope on the cooling energy consumption, the influence of window-to-wall ratio (WWR) was also examined. The surface area of a window exposed to sunlight can be a very critical parameter in cooling energy consumption. The higher the window surface area exposed to an outside environment with low thermal insulations, the higher will be the cooling energy consumption. A linear 
relationship between WWR and cooling energy consumption was quite evident from the results of this study. Large luxury flats are often provided with larger WWR compared to public housing in Hong Kong. Large windows can be visually aesthetic but it is also a major contributor for heat gain into the indoor environment. The provision for having large WWR should be provided with appropriate thermal insulations so as minimize the heat gain into the indoor space. At the same time, this study has indicated that reducing the WWR can be an efficient measure to reduce cooling energy consumption. Hence, it is important to strike a balance between visual aesthetics and cooling energy consumption as required.

It was indicated earlier that the number of very hot days and hot nights are increasing whereas the number of cold days is decreasing over the last hundred years in Hong Kong [5]. This trend is almost similar in other parts of the world, where there is a dramatic shift in the average daily temperature been recorded [4]. The increase in outdoor temperature as a result of climate change is driving the cooling energy demand in indoor environments. In order to reduce the cooling energy consumption, it is vital to reduce the indoor setpoint temperature. As indicated through this study there are significant energy saving potentials by changing the existing indoor set-point temperatures. Hence, it is urged to the global community to practice setting indoor set-point temperature above existing levels imminently so as to reduce the carbon emissions associated with building cooling energy. The confluence of strategies reported in this study can be a good reference point for building energy efficiency practitioners to improve upon existing knowledge and mitigate the carbon emission associated with the residential sector.

\section{Conclusions}

The electricity consumption for air conditioning of residential buildings located in sub-tropical climatic regions such as Hong Kong was identified as a major source of GHG emissions through this study. An increase of $13.1 \%$ in electricity consumption for the residential sector was recorded for a period between 2008 and 2018. With the increase in population and household size, the residential energy consumption in Hong Kong is expected to rise if adequate measures are not taken to curb the cooling energy demand. Carbon emission from buildings cooling energy consumption is a major constituent causing climate change. Strategizing energy efficiency measures to decarbonize the building sector, especially in high-rise cities such as Hong Kong, can have far-reaching benefits. This study proposed a hybrid simulation strategy that is a testament to the potential of integrating artificial intelligence techniques with a building energy simulation tool (EnergyPlus ${ }^{\mathrm{TM}}$ ) to predict the annual cooling energy consumption for the residential buildings in Hong Kong. The annual cooling energy prediction tool developed will serve as a reference for building energy efficiency practitioners to identify key relationships between building physical characteristics and operational strategies to reduce the cooling energy demand at a minimal time in comparison to traditional energy estimation methods.

The hybrid simulation model of this study can analyze the impacts of building materials, construction solutions, and indoor-outdoor temperature variations on the cooling energy consumed in apartments. The results of this study showed that using low thermal conductivity building materials for windows and external walls can reduce the annual cooling energy consumption by up to $8.19 \%$ and decreasing the window-to-wall ratio from $80 \%$ to $40 \%$ can give annual cooling energy savings of up to $18 \%$. Moreover, significant net annual cooling energy savings of $13.65 \%$ can be achieved by changing the indoor setpoint temperature from $24{ }^{\circ} \mathrm{C}$ to $26^{\circ} \mathrm{C}$. Putting global warming into perspective, however, when the outdoor temperature rises by $1{ }^{\circ} \mathrm{C}$, increases of $4 \%$ and $2.5 \%$ in annual cooling energy load from the existing levels are estimated for maintaining the indoor set-point temperatures at $24^{\circ} \mathrm{C}$ and $25.5^{\circ} \mathrm{C}$, respectively.

To conclude this section a few important insights to this study are drawn to improve the work further. The impact on cooling load due to interaction of buildings such as shading from a neighboring building has not been considered whereas the scenario where 
the building receives maximum solar heat gain was examined in this study. Shading is noted to reduce the cooling energy demand further in densely packed cooling dominant regions such as Hong Kong, which would be an additional benefit in terms of energy savings rather than a detrimental effect. Although, the addition of this component could improve the effectiveness of the proposed model when it is applied to buildings in different climatic regions. Future studies with respect to the expansion of the proposed methodology of this study to cover different scales of buildings under different climatic conditions shall increase the potentialities of this approach to develop more carbon-neutral buildings in the future. Furthermore, including cost analysis in the proposed methodology will aid stakeholders to implement energy-saving strategies that are cost-effective.

Author Contributions: Conceptualization, K.W.M. and L.T.W.; data curation, M.K.S.; formal analysis, M.K.S.; funding acquisition, K.W.M. and L.T.W.; investigation, M.K.S.; methodology, K.W.M. and L.T.W.; project administration, K.W.M. and L.T.W.; resources, K.W.M. and L.T.W.; software, M.K.S. and A.B.; supervision, K.W.M.; validation, M.K.S. and A.B.; visualization, M.K.S.; writing-original draft, M.K.S.; writing-review and editing, L.T.W. All authors have read and agreed to the published version of the manuscript.

Funding: This research was funded by the General Research Fund, University Grants Committee of HKSAR (Project no. PolyU P0005278/17E) and Research Institute for Smart Energy, The Hong Kong Polytechnic University.

Institutional Review Board Statement: Not applicable.

Informed Consent Statement: Not applicable.

Data Availability Statement: Data sharing not applicable.

Conflicts of Interest: The authors declare no conflict of interest.

\section{References}

1. Luber, G.; Knowlton, K.; Balbus, J.; Frumkin, H.; Hayden, M.; Hess, J.; McGeehin, M.; Sheats, N.; Backer, L.; Beard, C.B. Climate change impacts in the United States: The third national climate assessment. In National Climate Assessment Report; U.S. Global Change Research Program: Washington, DC, USA, 2014; pp. 220-256. [CrossRef]

2. Evens, A.; Garascia, M.; Isaacson, M. Utilities and health: Energy efficiency as a common link. Electr. J. 2017, 30, 10-14. [CrossRef]

3. Spandagos, C.; Ng, T.L. Equivalent full-load hours for assessing climate change impact on building cooling and heating energy consumption in large Asian cities. Appl. Energy 2017, 189, 352-368. [CrossRef]

4. Abergel, T.; Delmastro, C. Tracking Buildings 2020; International Energy Agency (IEA): Paris, France, 2020.

5. Observatory, H.K. Climate Change in Hong Kong-Extreme Weather Events. Available online: https://www.hko.gov.hk/en/ climate_change/obs_hk_extreme_weather.htm (accessed on 7 July 2021).

6. Albadry, S.; Tarabieh, K.; Sewilam, H. Achieving net zero-energy buildings through retrofitting existing residential buildings using PV panels. Energy Procedia 2017, 115, 195-204. [CrossRef]

7. Pérez-Lombard, L.; Ortiz, J.; Pout, C. A review on buildings energy consumption information. Energy Build. 2008, 40, 394-398. [CrossRef]

8. Swan, L.G.; Ugursal, V.I. Modeling of end-use energy consumption in the residential sector: A review of modeling techniques. Renew. Sustain. Energy Rev. 2009, 13, 1819-1835. [CrossRef]

9. Biswas, M.R.; Robinson, M.D.; Fumo, N. Prediction of residential building energy consumption: A neural network approach. Energy 2016, 117, 84-92. [CrossRef]

10. CENSTATD. Hong Kong Population Projections 2020-2069; Census and Statistics Department Hong Kong: Hong Kong, China, 2020.

11. World Population Prospects: 2018 Revision; Department of Economic and Social Affairs: New York, NY, USA, 2018.

12. Housing; Legislative Council Secretariat: Hong Kong, China, 2016; ISSH09/16-17.

13. Housing in Figures 2009-2013; Hong Kong Housing Authority, The Government of Hong Kong Special Administrative Region, China: Hong Kong, China, 2013.

14. Hong Kong's Climate Action Plan 2030+; Environment Bureau of the HKSAR Government and Steering Committee on Climate: Hong Kong, China, 2017.

15. Hong Kong Special Administrative Region; Hong Kong Energy End-use Data 2020: Hong Kong, China, 2020.

16. Zhao, H.-X.; Magoulès, F. A review on the prediction of building energy consumption. Renew. Sustain. Energy Rev. 2012, 16, 3586-3592. [CrossRef]

17. Ahmad, T.; Chen, H.; Guo, Y.; Wang, J. A comprehensive overview on the data driven and large scale based approaches for forecasting of building energy demand: A review. Energy Build. 2018, 165, 301-320. [CrossRef] 
18. Robinson, C.; Dilkina, B.; Hubbs, J.; Zhang, W.; Guhathakurta, S.; Brown, M.A.; Pendyala, R.M. Machine learning approaches for estimating commercial building energy consumption. Appl. Energy 2017, 208, 889-904. [CrossRef]

19. Li, Z.; Han, Y.; Xu, P. Methods for benchmarking building energy consumption against its past or intended performance: An overview. Appl. Energy 2014, 124, 325-334. [CrossRef]

20. Catalina, T.; Virgone, J.; Blanco, E. Development and validation of regression models to predict monthly heating demand for residential buildings. Energy Build. 2008, 40, 1825-1832. [CrossRef]

21. Chen, W.; Pourghasemi, H.R.; Kornejady, A.; Zhang, N. Landslide spatial modeling: Introducing new ensembles of ANN, MaxEnt, and SVM machine learning techniques. Geoderma 2017, 305, 314-327. [CrossRef]

22. Ahmad, M.W.; Mourshed, M.; Rezgui, Y. Trees vs Neurons: Comparison between random forest and ANN for high-resolution prediction of building energy consumption. Energy Build. 2017, 147, 77-89. [CrossRef]

23. Asadi, E.; da Silva, M.G.; Antunes, C.H.; Dias, L.; Glicksman, L. Multi-objective optimization for building retrofit: A model using genetic algorithm and artificial neural network and an application. Energy Build. 2014, 81, 444-456. [CrossRef]

24. Ascione, F.; Bianco, N.; De Stasio, C.; Mauro, G.M.; Vanoli, G.P. Artificial neural networks to predict energy performance and retrofit scenarios for any member of a building category: A novel approach. Energy 2017, 118, 999-1017. [CrossRef]

25. Kalogirou, S.A. Artificial neural networks in energy applications in buildings. Int. J. Low Carbon Technol. 2006, 1, 201-216. [CrossRef]

26. Paudel, S.; Elmtiri, M.; Kling, W.L.; Le Corre, O.; Lacarrière, B. Pseudo dynamic transitional modeling of building heating energy demand using artificial neural network. Energy Build. 2014, 70, 81-93. [CrossRef]

27. Guyot, D.; Giraud, F.; Simon, F.; Corgier, D.; Marvillet, C.; Tremeac, B. Overview of the use of artificial neural networks for energy-related applications in the building sector. Int. J. Energy Res. 2019, 43, 6680-6720. [CrossRef]

28. Kalogirou, S.; Neocleous, C.; Schizas, C. Building heating load estimation using artificial neural networks. In Proceedings of the 17th International Conference on Parallel Architectures and Compilation Techniques, Ontario, ON, Canada, 25-29 October 2008; p. 14.

29. Aydinalp, M.; Ugursal, V.I.; Fung, A.S. Modeling of the appliance, lighting, and space-cooling energy consumptions in the residential sector using neural networks. Appl. Energy 2002, 71, 87-110. [CrossRef]

30. Yezioro, A.; Dong, B.; Leite, F. An applied artificial intelligence approach towards assessing building performance simulation tools. Energy Build. 2008, 40, 612-620. [CrossRef]

31. Liu, Z.; Wu, D.; Liu, Y.; Han, Z.; Lun, L.; Gao, J.; Jin, G.; Cao, G. Accuracy analyses and model comparison of machine learning adopted in building energy consumption prediction. Energy Explor. Exploit. 2019, 37, 1426-1451. [CrossRef]

32. Huang, H.; Chen, L.; Hu, E. A neural network-based multi-zone modelling approach for predictive control system design in commercial buildings. Energy Build. 2015, 97, 86-97. [CrossRef]

33. Mihalakakou, G.; Santamouris, M.; Tsangrassoulis, A. On the energy consumption in residential buildings. Energy Build. 2002, 34, 727-736. [CrossRef]

34. Chou, J.-S.; Bui, D.-K. Modeling heating and cooling loads by artificial intelligence for energy-efficient building design. Energy Build. 2014, 82, 437-446. [CrossRef]

35. Gassar, A.A.A.; Cha, S.H. Energy prediction techniques for large-scale buildings towards a sustainable built environment: A review. Energy Build. 2020, 224, 110238. [CrossRef]

36. Runge, J.; Zmeureanu, R. Forecasting energy use in buildings using artificial neural networks: A review. Energies 2019, $12,3254$. [CrossRef]

37. Wong, L.T.; Mui, K.W.; Shi, K. Energy impact of indoor environmental policy for air-conditioned offices of Hong Kong. Energy Policy 2008, 36, 714-721. [CrossRef]

38. Cheung, C.K.; Fuller, R.J.; Luther, M.B. Energy-efficient envelope design for high-rise apartments. Energy Build. 2005, 37, 37-48. [CrossRef]

39. Lin, Z.; Deng, S. The outdoor air ventilation rate in high-rise residences employing room air conditioners. Build. Environ. 2003, 38, 1389-1399. [CrossRef]

40. Residential Air Conditioning: An Energy Efficiency Guide; EMSD: Hong Kong, China, 2010.

41. Kosar, D. Dehumidification system enhancements. ASHRAE J. 2006, 48, 48.

42. Wong, L.T.; Mui, K.W. An occupant load survey for residential buildings in Hong Kong. Int. J. Hous. Sci. Appl. 2006, 30, 195-204.

43. Tim Wong, L. Tiny affordable housing in Hong Kong. Indoor Built Environ. 2018, 27, 1159-1161. [CrossRef]

44. Standard Block Typical Floor Plans; Hong Kong Housing Authority: Hong Kong, China, 2021.

45. Aktacir, M.A.; Büyükalaca, O.; Yılmaz, T. A case study for influence of building thermal insulation on cooling load and air-conditioning system in the hot and humid regions. Appl. Energy 2010, 87, 599-607. [CrossRef]

46. Feng, Y. Thermal design standards for energy efficiency of residential buildings in hot summer/cold winter zones. Energy Build. 2004, 36, 1309-1312. [CrossRef]

47. Lam, J.C. Residential sector air conditioning loads and electricity use in Hong Kong. Energy Convers. Manag. 2000, 41, 1757-1768. [CrossRef]

48. Energy Standard for Buildings Except Low-Rise Residential Buildings; Atlanta: American Society of Heating; Refrigerating and Air-Conditioning Engineers: Atlanta, GA, USA, 2010. 
49. Bojic, M.; Yik, F.; Wan, K.; Burnett, J. Influence of envelope and partition characteristics on the space cooling of high-rise residential buildings in Hong Kong. Build. Environ. 2002, 37, 347-355. [CrossRef]

50. Wan, K.; Yik, F.H. Representative building design and internal load patterns for modelling energy use in residential buildings in Hong Kong. Appl. Energy 2004, 77, 69-85. [CrossRef]

51. Fumo, N. A review on the basics of building energy estimation. Renew. Sustain. Energy Rev. 2014, 31, 53-60. [CrossRef]

52. Hale, E.; Macumber, D.; Weaver, E.; Shekhar, D. Flexible Framework for Building Energy Analysis; National Renewable Energy Lab.(NREL): Golden, CO, USA, 2012.

53. Long, N.; Ball, B.; Goldwasser, D.; Parker, A.; Elling, J.; Davis, O.; Kruchten, D. Leveraging OpenStudio's Application Programming Interfaces; National Renewable Energy Lab.(NREL): Golden, CO, USA, 2013.

54. Roth, A.; Goldwasser, D.; Parker, A. There's a measure for that! Energy Build. 2016, 117, 321-331. [CrossRef]

55. Goldwasser, D.; Macumber, D.; Parker, A.; Lee, E.; Guglielmetti, R.; Brackney, L. The life cycle of an openstudio measure: Development, testing, distribution, and application. Proc. SimBuild 2016, 6, 222-229.

56. Fleming, K.; Long, N.; Swindler, A. Building Component Library: An Online Repository to Facilitate Building Energy Model Creation; National Renewable Energy Lab.(NREL): Golden, CO, USA, 2012.

57. Mui, K.W.; Wong, L.T. Cooling load calculations in subtropical climate. Build. Environ. 2007, 42, 2498-2504. [CrossRef]

58. Kumar, R.; Aggarwal, R.; Sharma, J. Energy analysis of a building using artificial neural network: A review. Energy Build. 2013, 65, 352-358. [CrossRef]

59. Biswas, M.R.; Robinson, M.D. Performance estimation of direct methanol fuel cell using artificial neural network. In Proceedings of the ASME International Mechanical Engineering Congress and Exposition, Houston, Texas, USA, 13-19 November 2015; p. V06BT07A022.

60. Tso, G.K.; Yau, K.K. Predicting electricity energy consumption: A comparison of regression analysis, decision tree and neural networks. Energy 2007, 32, 1761-1768. [CrossRef]

61. Torrecilla, J.; Otero, L.; Sanz, P. Optimization of an artificial neural network for thermal/pressure food processing: Evaluation of training algorithms. Comput. Electron. Agric. 2007, 56, 101-110. [CrossRef]

62. Hagan, M.T.; Menhaj, M.B. Training feedforward networks with the Marquardt algorithm. IEEE Trans. Neural Netw. 1994, 5, 989-993. [CrossRef]

63. Demuth, H.B.; Beale, M.H. Matlab Neural Network Toolbox: User's Guide; Mathworks: Portola Valley, CA, USA, 2010.

64. Kayri, M. Predictive abilities of bayesian regularization and Levenberg-Marquardt algorithms in artificial neural networks: A comparative empirical study on social data. Math. Comput. Appl. 2016, 21, 20. [CrossRef]

65. Chaipimonplin, T. Investigation internal parameters of neural network model for Flood Forecasting at Upper river Ping, Chiang Mai. KSCE J. Civ. Eng. 2016, 20, 478-484. [CrossRef]

66. Gouravaraju, S.; Narayan, J.; Sauer, R.A.; Gautam, S.S. A Bayesian regularization-backpropagation neural network model for peeling computations. Arxiv Prepr. Arxiv 2020, 2006, 16409.

67. Hirschen, K.; Schäfer, M. Bayesian regularization neural networks for optimizing fluid flow processes. Comput. Methods Appl. Mech. Eng. 2006, 195, 481-500. [CrossRef] 